\title{
Detection of sinkholes using 2D electrical resistivity imaging
}

\author{
Michael van Schoor* \\ CSIR, Division of Mining Technology, PO Box 91230, Auckland Park 2006, Johannesburg, South Africa
}

Received 16 July 2001; accepted 15 May 2002

\begin{abstract}
Sinkholes in dolomitic areas are notoriously difficult geophysical targets, and selecting an appropriate geophysical solution is not straightforward. Electrical resistivity imaging, or tomography (RESTOM) is well suited to mapping sinkholes because of the ability of the technique for detecting resistive features and discriminating subtle resistivity variations. RESTOM surveys were conducted at two sinkhole sites near Pretoria, South Africa. The survey areas are located in the dolomites of the Lyttelton Formation, which forms part of the Malamani Subgroup and Chuniespoort Group of the Transvaal Supergroup. The survey results suggest that RESTOM is an ideal geophysical tool to aid in the detection and monitoring of sinkholes and other subsurface cavities.
\end{abstract}

(C) 2002 Elsevier Science B.V. All rights reserved.

Keywords: (Electrical) resistivity tomography; Geoelectric imaging; RESTOM; Sinkhole; Cavity; Dolomite

\section{Introduction}

Selection of the correct geophysical tool for the detection of sinkholes and subsurface cavities is not always straightforward, due to the highly variable and unpredictable target characteristics. For example, the sinkhole structure may comprise highly weathered material where few or no subsurface cavities have developed, in which case it will be conductive relative to the country rock; and therefore it will be a very good target for electromagnetic (EM) methods. Alternatively, a mature sinkhole may consist predominantly of an air-filled cavity, making it highly resistive and possibly transparent to some EM meth-

\footnotetext{
${ }^{*}$ Tel.: +27-11-358-0124; fax: +27-11-482-1214.

E-mail address: mvschoor@csir.co.za (M. van Schoor).
}

ods such as transient electromagnetic (TEM) profiling. Although some cavities may remain covered with overburden, others often break through to the surface. Cavities can be partially or completely waterfilled and, depending on the composition of the water, have a resultant conductivity ranging from very conductive to relatively resistive, compared to host rock.

Successful application of the gravity method for the detection of sinkholes depends on a density contrast between the material filling the sinkhole and its surroundings. It is highly likely that only air-filled cavities will yield as unequivocal anomalous response. The ground-penetrating radar (GPR) method is often applicable to the mapping of disturbed near-surface zones, such as developing sinkholes and cavities. The presence of conductive overburden can, however, render a sinkhole almost 
undetectable to GPR. In many cases, however, GPR can be very definitive (Benson, 1995).

Resistivity Tomography (RESTOM) is one of the most promising techniques for solving the sinkhole problem. RESTOM is a proven imaging technique where the theory and application are well documented in geophysical research literature (Griffiths and Barker, 1993; Daily and Owen, 1991; Daily and Ramirez, 1992, 1995). Although RESTOM is a useful tool in mineral exploration, (Sasaki and Matsuo, 1993; van Schoor and Duvenhage, 2000), the technique is well suited to applications in the fields of geohydrology, environmental science and engineering (Spies and Ellis, 1995; Barker and Moore, 1998). There have been many applications of electrical resistivity methods to detecting sinkholes and cavities, for example, see Burger (1992) and Maillol et al. (1999).
In the following sections, two case studies are discussed to demonstrate the potential of RESTOM as a routine geophysical tool for the monitoring of sinkholes and other subsurface cavities. The survey sites are located in Valhalla near Centurion and Pretoria.

\section{Geological problem}

Fig. 1 shows a schematic plan view of Site \#1, which is located near Centurion, south of Pretoria, South Africa (also refer to Fig. 2). At this site, the surface expression of a known sinkhole with a diameter of about $30 \mathrm{~m}$ could be seen. The degree of subsidence was very low-probably no more than a few centimeters. The true extent of the sinkhole, and whether it contained any cavities, were unknown. There are no boreholes in the area under consider-
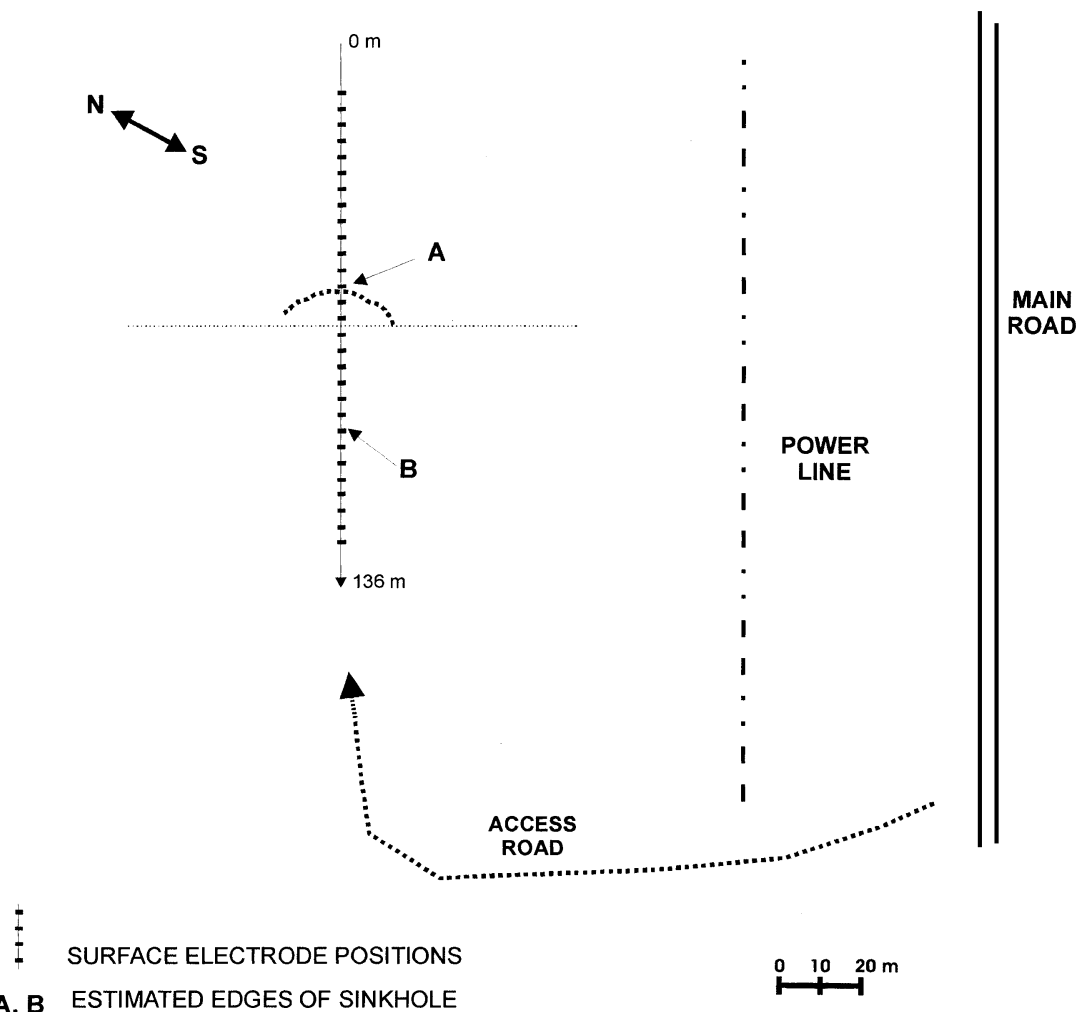

Fig. 1. Schematic plan view of Site \#1. A known sinkhole with a diameter of approximately $30 \mathrm{~m}$ is present at this site. The edges of the sinkhole (where minor subsidence has occurred) are visible in places on the surface and are indicated by markers A and B. 
TO

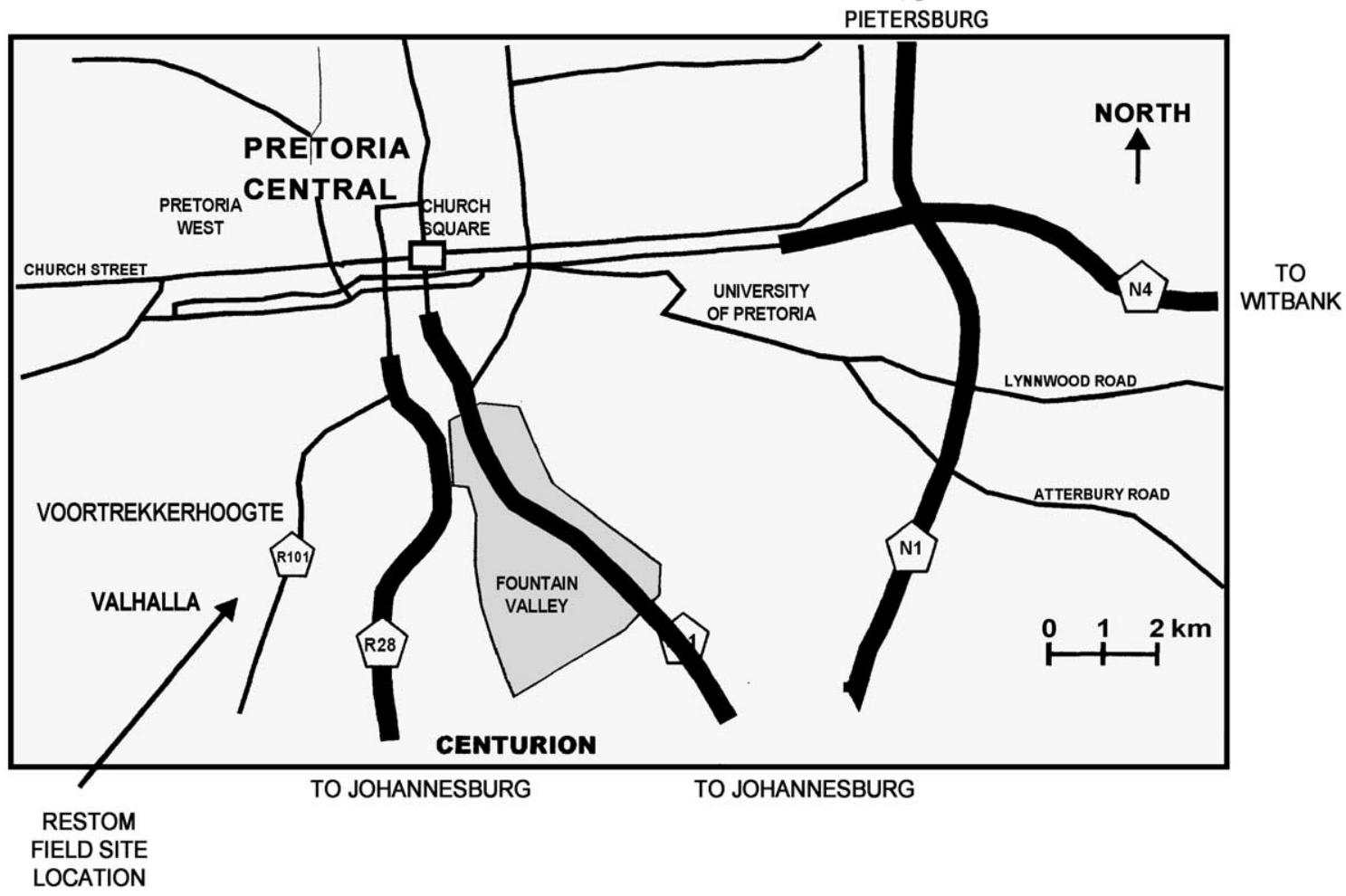

Fig. 2. Map showing the location of the RESTOM survey sites near Pretoria.

ation. The focus of this survey was primarily of a qualitative nature and the objective was to determine if RESTOM could be used to map near surface sinkholes in the Centurion area.

\section{Resistivity tomography survey}

At Site \#1, a RESTOM survey was conducted using the dipole-dipole electrode configuration. A
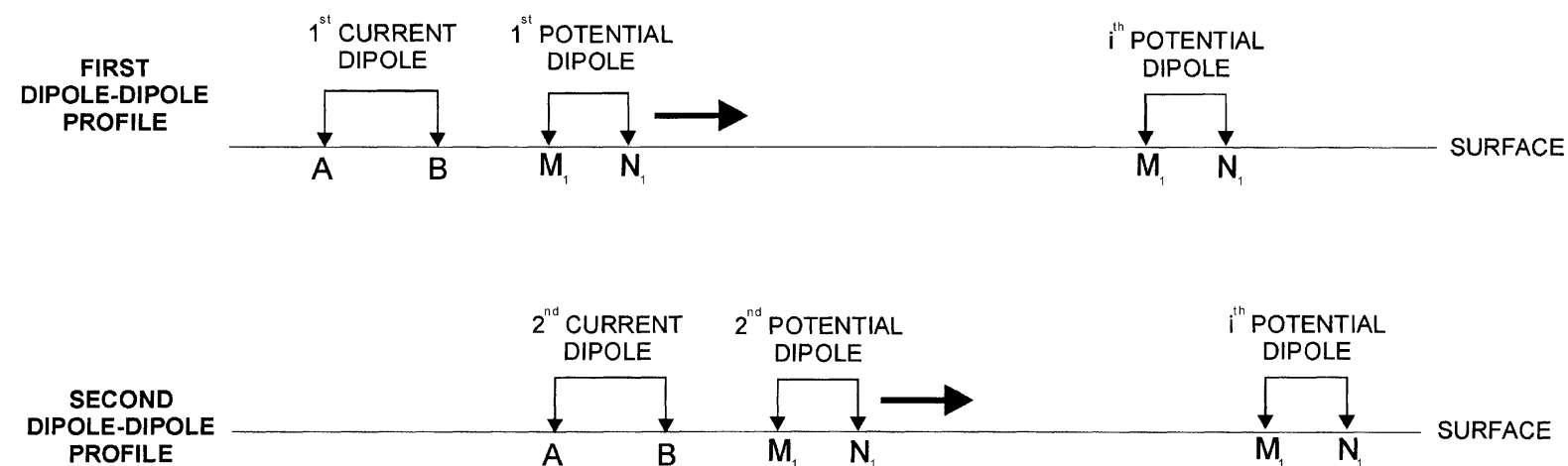

Fig. 3. Schematic showing the basic principle of conducting a conventional dipole-dipole resistivity survey. Note that, for a given profile, the $\mathrm{AB}$ position is fixed and measurements are recorded at various $\mathrm{MN}$ positions along the survey line. Note that for consecutive profiles the $\mathrm{AB}$ location shifts incrementally in the profiling direction. 
conventional in-line surface profile was surveyed approximately through the center of the sinkhole's surface expression. The survey was designed such that the topographic variation along the survey line was practically negligible. The RESTOM survey procedure involved introducing a direct-current field into the earth through two surface electrodes, A and B, spaced $8 \mathrm{~m}$ apart and positioned at one end of the profile (refer to Fig. 3). Potential difference measurements were acquired for several adjacent potential electrode pairs, $\mathrm{M}_{\mathrm{i}}$ and $\mathrm{N}_{\mathrm{i}}$, at incrementally increasing distances away from the current electrode positions. An MN electrode spacing of $4 \mathrm{~m}$ was used. The AB positions were then advanced by $8 \mathrm{~m}$ and a further potential difference profile was acquired. This process was repeated until the $\mathrm{AB}$ pair had advanced about 30 $\mathrm{m}$ past the area of interest (perceived sinkhole edge). A total profile length of approximately $100 \mathrm{~m}$ was surveyed.

The data set was used as input to an iterative inversion scheme. A commercially available software package RESITOMO developed by DMT (Germany) (Kemna et al., 1996) was used for the inversion. The 2D finite element inversion scheme is based on the forward modelling algorithm of Dey and Morrison (1979) and the modified Multiplicative Simultaneous Iterative Reconstruction Technique (MSIRT) of Gilbert (1972), as described in Kemna et al. (1996).

During the inversion process the RMS value of the data error (difference between data and updated model response) is used as a criterion to judge the conver- gence at each iteration step (Kemna et al., 1996). If the data error RMS value or the relative decrease of the data error RMS value drop below a pre-defined level the inversion is said to converge and the process is terminated. Values of $2 \%$ and 0.01 were used as minimum values for the data error RMS and minimum relative decrease of data error RMS, respectively.

\section{Discussion of Site \#1 results}

Fig. 4 shows the resulting RESTOM image from the survey conducted at Site \#1. The presence of the sinkhole manifests itself in the output image in the form of two basin shaped zones of relatively high conductivity (between electrode positions 9 and 18, and positions 18 and 25). The depth extent of these two zones appears to be about 15 and $10 \mathrm{~m}$, respectively. The calculated resistivity values for these zones are in the range $250-600 \Omega \mathrm{m}$, compared to a background resistivity in the range 1200-3000 $\Omega \mathrm{m}$. These zones are interpreted to be highly weathered dolomite. It is interesting to note that the perceived 'edges' of the sinkhole (as inferred from the observed surface cracks) occur directly above the regions of deepest weathering.

There are two smaller features of interest on the output image. The first is the sudden crossover from a localized conductive to resistive zone that can be seen near the surface at position A. The second is a small, near surface localized conductive zone at electrode

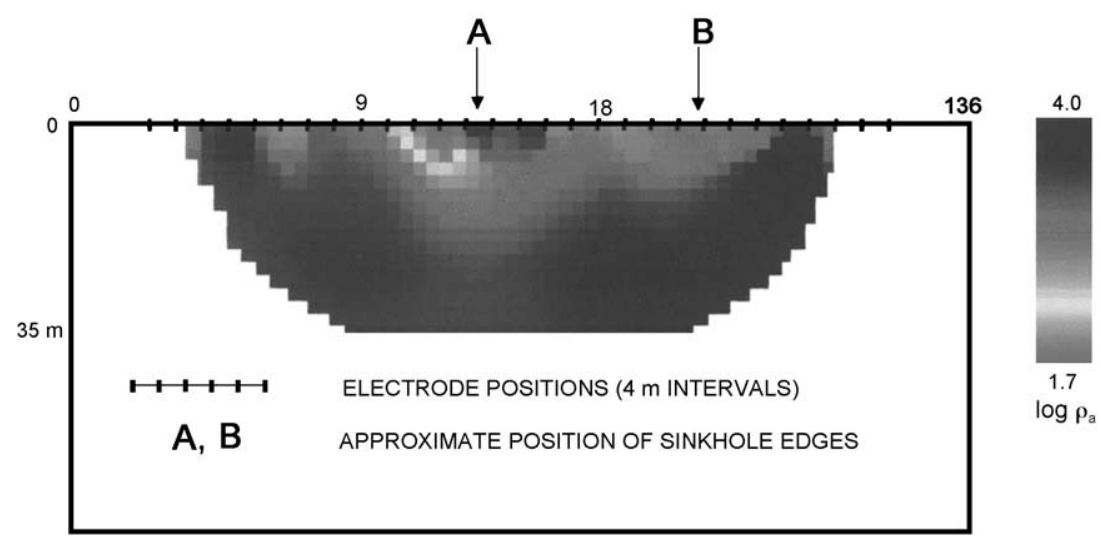

Fig. 4. RESTOM output image from Site \#1. On the resulting image the blue represents high resistivity, while red and yellow represent low resistivity or high conductivity. The logarithm of the estimated pixel resistivity values is displayed. 


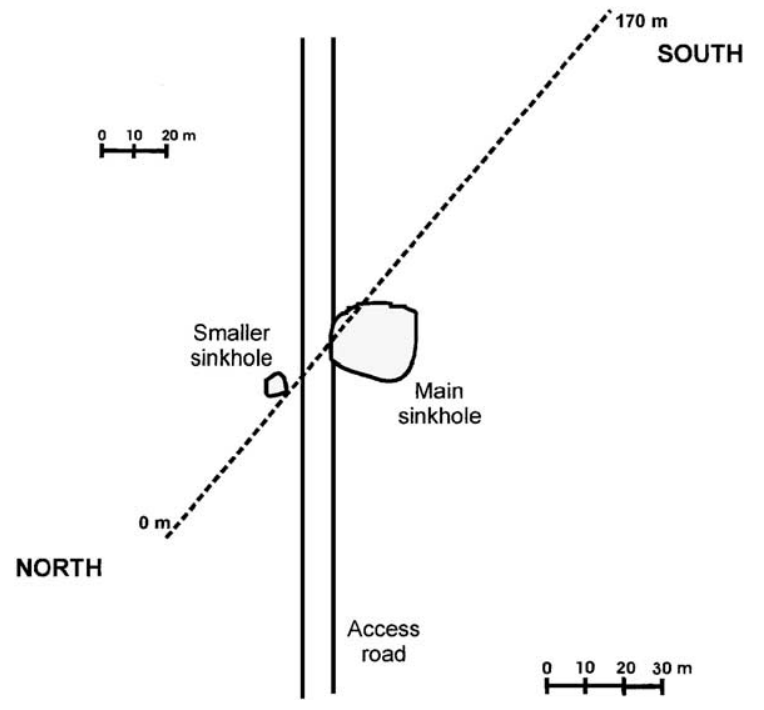

Fig. 5. Schematic plan view of Site \#2.

position 7. The former could be related to the very sharp conductivity contrast at the edge of the sinkhole structure or, alternatively, the response of an undetected buried water pipe. The other anomaly at electrode position 7 is probably another, smaller sinkhole.
This feature, like the previously mentioned sinkholes, also has a resistivity in the range 200-600 $\Omega \mathrm{m}$. Unfortunately, to date no drilling has been conducted to verify the interpretations.

\section{Geological problem}

Fig. 5 shows a schematic plan view of Site \#2, located within $5 \mathrm{~km}$ of the first site. During February and March 2000, the Centurion area was subjected to many occurrences of sinkhole subsidence following the heavy rains during the preceding summer months. This site was an example of such an occurrence. The tarred road shown on the map provides the access to a government building located approximately $1 \mathrm{~km}$ to the south. The two sinkholes indicated, one on either side of the road, appeared literally overnight during March 2000 (also refer to the photograph in Fig. 6).

The objective of the survey was to determine if the RESTOM technique could image the visible sinkholes, and to determine to what extent the subsurface below the tarred road was affected by the sinkholes. That is, were the two known sink-

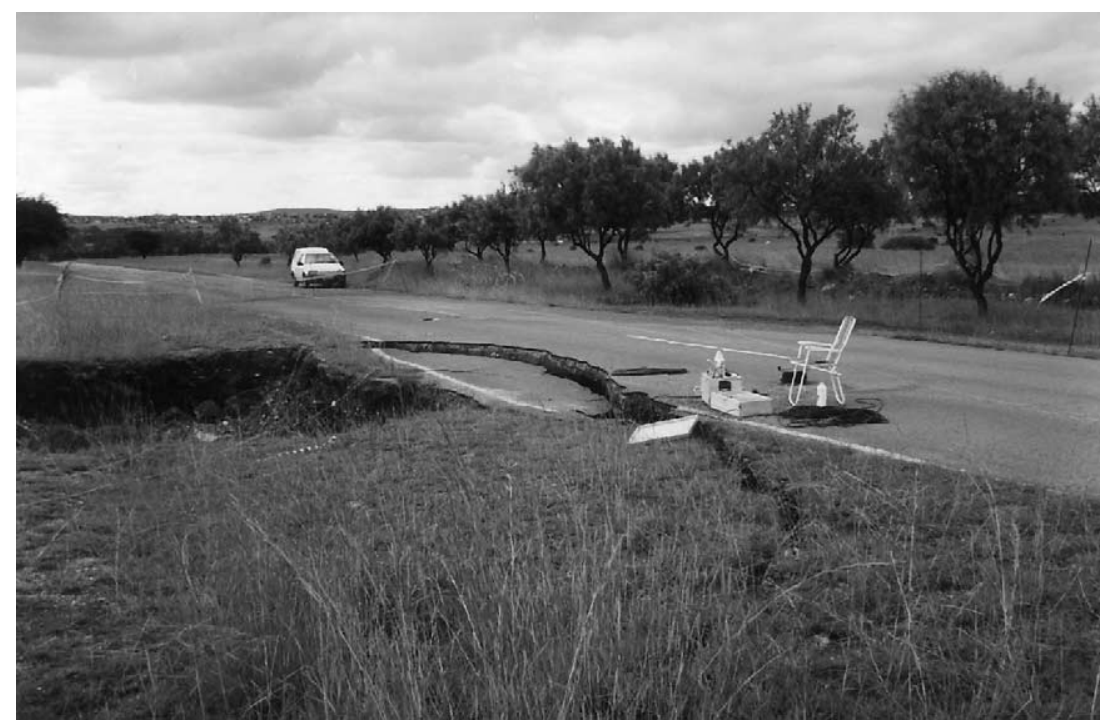

Fig. 6. Photograph showing the view from electrode position 19 and looking north over the bigger of the sinkholes in the direction of the start of the profile (position 1). Evidence of the smaller of the two holes (at electrode position 13) can be seen in the tree on the other side of the road that dropped vertically downwards so that its crown just protrudes above the ground. 


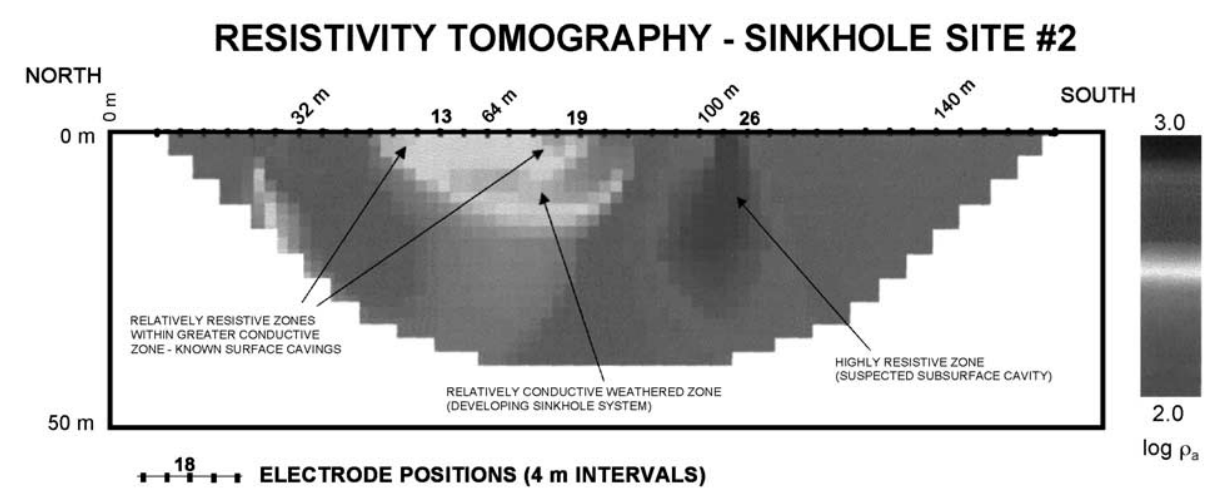

Fig. 7. RESTOM image resulting from the survey at Site \#2.

holes interconnected and merely the surface expression of a larger problem?

\section{Resistivity tomography survey}

The survey approach described above was also used at the second site. The same survey parameters ( $\mathrm{AB}, \mathrm{MN}$ and station spacing) were used, however, a much longer profile line was defined for this survey. The profile started approximately $50 \mathrm{~m}$ north of the smaller sinkhole and extended to approximately $80 \mathrm{~m}$ past the southern edge of the larger sinkhole. The total profile length was of the order of $170 \mathrm{~m}$. RESITOMO was again used to invert the data acquired using the same inversion control parameters as before.

\section{Discussion of Site \#2 results}

The image in Fig. 7 clearly maps the sinkhole structure that affected the road at this site. The two cavities can be seen as two smaller, locally resistive zones (at electrode positions 11-13 and 16-19, respectively), within the basin-shaped zone. This basin, with a resistivity in the range $250-350 \Omega \mathrm{m}$ represents a zone of highly conductive weathered dolomite. The background resistivity is approximately $500-700 \Omega \mathrm{m}$. It is possible that the two cavities (are interconnected and that they form part of the same weathered zone).
A prominent, highly resistive feature (800-1000 $\Omega \mathrm{m})$ is visible below electrode positions 25 and 26 . This feature appears to have a depth extent of 10-20 $\mathrm{m}$. Judging from the large resistivity contrast, it is probable that this anomaly is the response of an airfilled cavity. There are, however, no surface features indicative of the existence of a subsurface cavity. As this anomaly is located a safe distance from existing roads and buildings, there was no urgency to drill; and consequently, confirmation of the interpretation was not possible.

The relatively high conductive zone on the left edge of the image (below electrodes 1-4) could be the response of a further highly weathered zone. Due to a lack of sufficient coverage towards the north of the line, a confident analysis of this anomaly could not be carried out.

\section{Conclusions}

The results presented in this paper illustrate that RESTOM is a geophysical tool well suited to the detection and mapping of known sinkholes in dolomitic areas. The technique is capable of discriminating between developing sinkholes, where the target is primarily conductive weathered material, and mature sinkholes comprising resistive air-filled cavities. Such cavities may be water-filled, in which case they are likely to yield conductive anomalies as the water would, in all likelihood, be significantly more conductive than unweathered dolomite. Both 
situations provide good targets for delineation using the RESTOM method.

\section{References}

Barker, R., Moore, J., 1998. The application of time-lapse electrical tomography in groundwater studies. Lead. Edge 17 (10), 1454 1458.

Benson, A.K., 1995. Applications of ground penetrating radar in assessing some geological hazards: examples of groundwater contamination, faults, cavities. J. Appl. Geophys. 33, 177-193.

Burger, H.R., 1992. Exploration Geophysics of the Shallow Subsurface Prentice-Hall, Englewood Cliffs, NJ, 489 pp.

Daily, W., Owen, E., 1991. Crosshole resistivity tomography. Geophysics 56, 1228-1235.

Daily, W., Ramirez, A., 1992. Electrical resistivity tomography of vadose water movement. Water Resour. Res. 28, 1429-1442.

Daily, W., Ramirez, A., 1995. Environmental process tomography in the United States. Chem. Eng. J. 56, 159-165.

Dey, A., Morrison, H.F., 1979. Resistivity modelling for arbitrarily shaped two-dimensional structures. Geophys. Prospect. 27, $106-136$
Gilbert, P., 1972. Iterative methods for three-dimensional reconstruction of an object from projections. J. Theor. Biol. 36, $105-117$.

Griffiths, D.H., Barker, R.D., 1993. Two-dimensional resistivity imaging and modeling in areas of complex geology. J. Appl. Geophys. 29, 211-226.

Kemna, A., Engels, O.G., Martin, U.I., 1996. RESITOMO Resistivity Tomography v 2.0 User Manual, Software Package for 2.5D-Modelling and 2D-Inversion of DC-Resistivity Measurements. Harbour Dom GmbH, Köln, Germany.

Maillol, J.M., Seguin, M.-K., Gupta, O.P., Akhauri, H.M., Sen, N., 1999. Electrical resistivity tomography survey for delineating uncharted mine galleries in West Bengal, India. Geophys. Prospect., Eur. Assoc. Geosci. Eng. 47, 103-116.

Sasaki, Y., Matsuo, K., 1993. Surface-to-tunnel resistivity tomography at the Kamaishi Mine. Butsuri-Tansa 46, 128-133.

Spies, B., Ellis, R., 1995. Cross-borehole resistivity tomography of a pilot sale, in-situ vitrification test. Geophysics 60, 886-898.

Van Schoor, M., Duvenhage, D., 2000. Comparison of crosshole radio imaging and electrical resistivity tomography for mapping out disseminated sulphide mineralisation at a surface test site in Mpumalanga, South Africa. Explor. Geophys. 30, 3-4. 